\title{
Effects of the reciprocal grafting on the photosynthesis of two genotypes tomato offspring under selenium stress
}

\author{
Shiyao Shan ${ }^{1}$, Huizhong Luo ${ }^{1}$, Jinpeng $\mathrm{Zhu}^{2}$, Zhiyu $\mathrm{Li}^{2}$ and Huanxiu $\mathrm{Li}^{1}{ }^{*}$ \\ ${ }^{1}$ Institute of Pomology and Olericulture, Sichuan Agricultural University, Chengdu, Sichuan, 611130, China \\ ${ }^{2}$ College of Horticulture, Sichuan Agricultural University, Chengdu, Sichuan, 611130, China
}

\begin{abstract}
To study the effects of the reciprocal grafting on the photosynthesis of two genotypes tomato offspring under selenium stress, red ball cherry tomato cherry 5-5-1 and yellow ball cherry tomato yellow RTY-3-2 post-grafting generation (red scion, red rootstock, yellow scion and yellow rootstock) and seedlings (red CK and yellow CK) planted in $10 \mathrm{mg} \mathrm{kg}^{-1}$ selenium soil, and the pot experiment was carried out to study the effects of the reciprocal grafting on the growth characteristics and the photosynthesis of tomato offspring under selenium stress. The results showed that grafting increased the fresh weight of the organs of the offspring, the ratio of root to shoot, and the functional activity of the roots of the plants, which was conducive to the growth of tomato offspring. Simultaneously, it could effectively improve the photosynthetic capacity of grafted offspring leaves at the seedling stage. The grafted offspring of rootstocks had the best effect on improving the net photosynthetic rate, stomatal conductance and transpiration rate and stomatal conductance of tomato leaves, and decreased intercellular $\mathrm{CO}_{2}$ concentration. Among them, the best effect of yellow rootstock was to provide ideas and theoretical basis for the production of seleniumenriched tomatoes in the selenium-deficient areas in the future.
\end{abstract}

\section{Introduction}

Tomato (Solanum Lycopersicon L.) is an annual or perennial herb of Solanum in Solanaceae, which is rich in nutrient. It is an important vegetable widely cultivated and occupies an important position in the annual supply of vegetables [1]. Selenium (Se) plays an important role in human health, and it is a safer way to supplement Se by eating plants with high Se content. Se has a dual effect on the growth and development of plants. In low concentration, it promoted growth, in high concentration, it inhibited growth, and in excess, it caused toxicity [2]. When the concentration of Se in the solution was lower than $0.1 \mathrm{mg} \mathrm{L}^{-1}$, Se promoted the growth of tomato seedlings, showed the best growth when $0.05 \mathrm{mg} \mathrm{L}^{-1}$, and inhibited the growth of tomato seedlings when it was higher than $0.5 \mathrm{mg} \mathrm{L}^{-1}$. Application of $500-1000 \mathrm{mg} \mathrm{L}^{-1}$ sodium selenite solution on the garlic leaves could strengthen photosynthetic rate, thus significantly increased garlic yield. However, when the spraying concentration exceeded $1500 \mathrm{mg} \mathrm{L}^{-1}$, symptoms of Se poisoning were observed, resulting in decreased yield and quality [4].

After grafting scion and rootstock, the growth of the rootstock and the physiological characteristics of the rootstock have many effects due to the root-replacement effect. The study found that the plant height, stem diameter, aboveground fresh weight and root weight of pepper seedlings were all significantly higher than that of self-rooted pepper after grafting, indicating that grafting improved the plant growth [5]. Studies had pointed out that grafting rootstock could affect the net photosynthetic rate $(\mathrm{Pn})$ of scion, and then indirectly affect the activity of the whole plant [6]. Under copper stress, the biomass of grafted melon seedlings were higher than that of selfrooted seedlings, and the photosynthetic pigment content was higher than that of self-rooted seedlings. Pn, stomatal conductance (Gs), intercellular $\mathrm{CO}_{2}$ concentration $(\mathrm{Ci})$, and leaf transpiration rate $(\mathrm{Tr})$ were significantly greater than those of self-rooted seedlings [7]. The rapeseed as a rootstock grafted with amaranth and self-emergence grafting could increase the biomass of the progeny of the leek and increase the accumulation of cadmium [8]. Grafting improved the photosynthesis of the offspring of Solauum photeinocarpum [9].

In view of this, the experiment was carried out by grafting two genotypes of tomato to obtain the offspring, to study the growth characteristics and photosynthetic ability of the two genotypes of cherry tomato grafted offspring, in order to screen a better quality and strong resistance. The grafting treatment method provides ideas and theoretical basis for the production of high quality and efficient tomato cultivation in the future.

\section{Materials and Method}

\subsection{Materials collection}

*Corresponding author's e-mail: 479942014@qq.com 
Red cherry tomato was red ball cherry tomato cherry 55-1, and yellow cherry tomato was yellow ball cherry tomato yellow RTY-3-2, all from Sichuan Agricultural University vegetable research group, which were infinite growth types of multi-generation self-crossing material. In May 2016, two genotype tomato plants were planted, processed, grown in normal soil, and kept in reserve (grafted offspring). The processing methods were as follows. (1) Red cherry tomatoes were not grafted (the offspring was red $\mathrm{CK}$ ): the red cherry tomato seedlings were directly transplanted and planted. (2) The yellow cherry tomatoes were not grafted (the offspring was yellow CK): the yellow cherry tomato seedlings were directly transplanted and planted. (3) Red cherry tomato as rootstock (offspring was red rootstock) and yellow cherry tomato as scion (offspring was yellow scion) grafting: red cherry tomato and yellow cherry tomato seedlings were cut from the ground about $12 \mathrm{~cm}$, red cherry tomato seedlings lower seedling $(12 \mathrm{~cm})$ was used as the rootstock, and the upper seedling $(8 \mathrm{~cm})$ of the yellow cherry tomato was grafted as the scion, and the rootstock leaves and the shoots were retained. (4) Yellow cherry tomato as rootstock (offspring was yellow rootstock) and red cherry tomato as scion (offspring was red scion) grafting: red cherry tomato and yellow cherry tomato seedlings were cut from the ground about $12 \mathrm{~cm}$, yellow cherry tomato seedlings lower seedlings $(12 \mathrm{~cm})$ were used as rootstocks, and the upper seedlings $(8 \mathrm{~cm})$ of red cherry tomatoes were grafted as scions, retaining rootstock leaves and shoots.

The grafting method was cleft method, and a plastic tape having a width of about $1 \mathrm{~cm}$ and a length of $20 \mathrm{~cm}$ was used for binding, so that the joint portion of the rootstock and the scion were firmly attached. Watering at the initial stage of grafting and maintaining the soil water holding capacity of $80 \%$, materials were covered with a mulch to moisturize, and covered it with a sunshade net. After 10 days, the film and shading net were gradually removed, and the bound plastic film was removed. After grafting, all plants were planted in soils free of Se. Irregular watering according to the actual soil moisture conditions ensures that soil moisture is maintained at about $80 \%$ of the field water holding capacity. Before the initial flowering period, tomatoes were placed on a wellgrowth bud bag to prevent out crossing. Offspring seedlings of non-grafting, scion and rootstock of reciprocal grafting were collected and preserved after the maturity.

\subsection{Experimental design}

The soil was air-dried, ground and passed through a 5$\mathrm{mm}$ sieve. Each plastic pot $(300 \mathrm{~cm}$ high, $40 \mathrm{~cm}$ in diameter) was filled with $18 \mathrm{~kg}$ of ground soil, applied Se solution in the form of $\mathrm{Na}_{2} \mathrm{SeO}_{3} 5 \mathrm{H}_{2} \mathrm{O}$ to make the concentration of Se in the pot $10 \mathrm{mg} \mathrm{kg}^{-1}$, and mixed well with the soil. All pots were watered every day to keep the soil moisture about $80 \%$. After naturally placing the balance for 4 weeks, soil mixed again and set aside. The collected grafting offspring seeds were soaked and germinated. When 4 leaves and 1 heart were used, the tomato seedlings with uniform growth were transplanted into a pot with $10 \mathrm{mg} \mathrm{kg}^{-1}$ Se soil, $17 \mathrm{~cm} \times 20 \mathrm{~cm}$ (height $\times$ diameter). The small flowerpots were filled with $3 \mathrm{~kg}$ of Se soil, and 3 plants were transplanted per pot, and each treatment was repeated 6 times, and the relevant index of the seedling stage was determined. The positions of pots and pots were exchanged irregularly throughout the growth process to attenuate the effects of marginal effects, and weeds were removed in time to prevent pests and diseases.

\subsection{Project determination}

Growth target: after transplanting for one month, plant height, root length, stem base diameter, root weight, stem weight, and leaf weight were measured. Photosynthesis: plant leaves $\mathrm{Pn}, \mathrm{Gs}, \mathrm{Ci}$ and $\mathrm{Tr}$ were measured at 9:00 am and 11:00 am using a Li-6400 portable photosynthetic apparatus.

\subsection{Statistical analysis}

Statistical analysis was performed on the test data using Excel 2010, and the data was subjected to significant analysis using SPSS software (LSD method).

\section{Results and Discussion}

\subsection{The growth index of two cherry tomatoes grafting offspring}

The test showed (Table 1) that under the Se stress, the order of plant height of cherry tomato was: red scion $>$ red rootstock $>$ yellow scion $>$ red $\mathrm{CK}>$ yellow $\mathrm{CK}>$ yellow rootstock. Among them, red scion had the highest plant height in red tomato, $32.5 \%$ higher than red CK, and significantly different from control and other treatments. Yellow scion was $4.3 \%$ higher than yellow $\mathrm{CK}$, but the difference was not significant compared with the control difference. In terms of root length, the root length of red rootstock was the longest in red tomato and $32.8 \%$ higher than red CK. There was no significant difference between yellow scion and yellow rootstock, but they were significantly higher than the control group, respectively than yellow $\mathrm{CK} 12.3 \%$ and $23.1 \%$ higher. In terms of stem base diameter, red scion and red rootstock were $22.6 \%$ and $22.3 \%$ lower than red $\mathrm{CK}$, and the difference was significant. Yellow CK and yellow scion were not significantly different, while yellow rootstock was significantly higher than yellow CK, 13.8\% higher than yellow CK. In terms of root fresh weight, red scion and red rootstocks were $48.7 \%$ and $34.0 \%$ higher than red $\mathrm{CK}$, respectively, and they were significantly different from each other. Yellow scion and yellow rootstock were $59.9 \%$ and $119.2 \%$ higher than yellow $\mathrm{CK}$, and they were significantly different from each other. In terms of stems fresh weight, red scion was $54.7 \%$ higher than red $\mathrm{CK}$, and the difference was significant. There was no significant difference in stem fresh weight of yellow scion and yellow rootstock, which were $10.4 \%$ 
and $15.4 \%$ higher than yellow CK. In terms of leaf fresh weight, red rootstock was $16.2 \%$ lower than red CK, and the difference was significant. Yellow scion and yellow rootstock were significantly higher than yellow CK, which was $20.2 \%$ and $36.4 \%$ higher than yellow CK.

Table 1. The growth index of two cherry tomatoes grafting offspring.

\begin{tabular}{ccccccc}
\hline Treatment & $\begin{array}{c}\text { Plant height } \\
(\mathrm{cm})\end{array}$ & $\begin{array}{c}\text { Root length } \\
(\mathrm{cm})\end{array}$ & $\begin{array}{c}\text { Stem base } \\
\text { diameter } \\
(\mathrm{cm})\end{array}$ & $\begin{array}{c}\text { Root fresh weight } \\
(\mathrm{g})\end{array}$ & $\begin{array}{c}\text { Stem fresh } \\
\text { weight } \\
(\mathrm{g})\end{array}$ & $\begin{array}{c}\text { Leaf fresh } \\
\text { weight } \\
(\mathrm{g})\end{array}$ \\
\hline Red CK & $49.5 \pm 2.2 \mathrm{~b}$ & $12.5 \pm 1.7 \mathrm{~b}$ & $7.34 \pm 0.4 \mathrm{a}$ & $3.24 \pm 0.172 \mathrm{c}$ & $14.735 \pm 1.047 \mathrm{~b}$ & $20.236 \pm 1.599 \mathrm{a}$ \\
Red scion & $65.6 \pm 2.9 \mathrm{a}$ & $12.5 \pm 1.4 \mathrm{~b}$ & $5.68 \pm 0.22 \mathrm{~b}$ & $4.819 \pm 0.193 \mathrm{a}$ & $22.799 \pm 1.253 \mathrm{a}$ & $21.851 \pm 1.801 \mathrm{a}$ \\
Red rootstock & $51.2 \pm 1.5 \mathrm{~b}$ & $16.6 \pm 1.1 \mathrm{a}$ & $5.7 \pm 0.29 \mathrm{~b}$ & $4.342 \pm 0.188 \mathrm{~b}$ & $14.404 \pm 0.423 \mathrm{~b}$ & $16.956 \pm 1.161 \mathrm{~b}$ \\
Yellow CK & $48.7 \pm 1.9 \mathrm{~b}$ & $13 \pm 1.3 \mathrm{~b}$ & $5.07 \pm 0.13 \mathrm{~b}$ & $2.987 \pm 0.424 \mathrm{c}$ & $11.25 \pm 0.645 \mathrm{~b}$ & $19.08 \pm 1.586 \mathrm{c}$ \\
Yellow scion & $50.8 \pm 2.1 \mathrm{a}$ & $14.6 \pm 1.6 \mathrm{a}$ & $5.21 \pm 0.05 \mathrm{~b}$ & $4.777 \pm 0.22 \mathrm{~b}$ & $12.425 \pm 0.922 \mathrm{a}$ & $22.939 \pm 1.226 \mathrm{~b}$ \\
Yellow rootstock & $47.4 \pm 0.8 \mathrm{~b}$ & $16 \pm 0.9 \mathrm{a}$ & $5.77 \pm 0.44 \mathrm{a}$ & $6.548 \pm 0.149 \mathrm{a}$ & $12.982 \pm 0.855 \mathrm{a}$ & $26.031 \pm 2.156 \mathrm{a}$ \\
\hline
\end{tabular}

Note: Different lowercase letters indicate significant differences at the $P<0.05$ level, and the table below is the same.

\subsection{The photosynthetic capacity of two cherry tomatoes grafted offspring leaves}

It could be seen from Table 2 that the order of Pn, Gs and $\mathrm{Tr}$ in the seedling leaves of the two grafted cherry tomatoes were: red rootstock $>$ yellow rootstock $>$ yellow scion $>$ red $\mathrm{CK}>$ red scion $>$ yellow $\mathrm{CK}$. Among them, Pn of red rootstock increased by $84.1 \%$ compared with red CK. Yellow scion and yellow rootstock increased by $238.8 \%$ and $306.3 \%$ compared with yellow CK. Gs of red rootstock was significantly higher than red CK, which was $159.7 \%$ higher than the red CK. Yellow scion and yellow rootstock were significantly higher than yellow CK, which was $300.0 \%$ and $325.0 \%$ higher than yellow CK. For Ci, red rootstock was significantly lower than red $\mathrm{CK}$, which was $2.3 \%$ and $67.9 \%$ lower than that of red CK. Ci of yellow scions was significantly higher than that of yellow CK, which was $261.1 \%$ higher than that of yellow CK. Yellow rootstock was significantly lower than yellow CK, which was $49.0 \%$ lower than yellow CK. Tr of red rootstock was $110.2 \%$ higher than red $\mathrm{CK}$. Yellow scion and yellow rootstocks were $214.3 \%$ and $278.0 \%$ higher than yellow CK. It indicated that the grafting of rootstock increased the Pn, Gs and Tr of the leaves of tomato plants, and reduced $\mathrm{Ci}$.

Table 2. The photosynthetic capacity of two cherry tomatoes grafted offspring leaves.

\begin{tabular}{ccccc}
\hline \multirow{2}{*}{ Treatment } & $\mathrm{Pn}$ & $\mathrm{Gs}$ & $\mathrm{Ci}$ & $\mathrm{Tr}$ \\
\cline { 2 - 5 } & $\left(\mu \mathrm{mol} \mathrm{CO} / \mathrm{m}^{2} / \mathrm{s}\right)$ & $\left(\mathrm{mol} \mathrm{H}_{2} \mathrm{O} / \mathrm{m}^{2} / \mathrm{s}\right)$ & $\left(\mathrm{mmol} \mathrm{CO}_{2} / \mathrm{mol}\right)$ & $\left(\mathrm{mol} \mathrm{H}_{2} \mathrm{O} / \mathrm{m}^{2} / \mathrm{s}\right)$ \\
\hline Red CK & $15.56 \pm 0.667 \mathrm{~b}$ & $0.071 \pm 0.009 \mathrm{~b}$ & $46.479 \pm 1.143 \mathrm{a}$ & $3.091 \pm 0.123 \mathrm{~b}$ \\
Red scion & $14.371 \pm 1.612 \mathrm{~b}$ & $0.064 \pm 0.005 \mathrm{~b}$ & $45.425 \pm 1.775 \mathrm{~b}$ & $3.021 \pm 0.117 \mathrm{~b}$ \\
Red rootstock & $28.647 \pm 1.911 \mathrm{a}$ & $0.178 \pm 0.008 \mathrm{a}$ & $14.923 \pm 0.867 \mathrm{c}$ & $6.498 \pm 0.09 \mathrm{a}$ \\
Yellow CK & $6.706 \pm 0.698 \mathrm{c}$ & $0.036 \pm 0.006 \mathrm{c}$ & $31.668 \pm 1.891 \mathrm{~b}$ & $1.515 \pm 0.088 \mathrm{c}$ \\
Yellow scion & $22.721 \pm 0.976 \mathrm{~b}$ & $0.144 \pm 0.012 \mathrm{~b}$ & $114.353 \pm 1.188 \mathrm{a}$ & $4.762 \pm 0.074 \mathrm{~b}$ \\
Yellow rootstock & $27.245 \pm 1.705 \mathrm{a}$ & $0.153 \pm 0.009 \mathrm{a}$ & $16.163 \pm 1.111 \mathrm{c}$ & $5.727 \pm 0.169 \mathrm{a}$ \\
\hline
\end{tabular}

\section{Discussion and conclusions}

Plant height, root length, stem base diameter, and fresh weight of roots and leaves are the targets of plant growth vigor [10]. After grafting, the rootstock had a developed root system, which promoted the growth of the aboveground part, thereby changing the growth and metabolism of the scion, and had strong resistance to stress and the ability to absorb fertilizer and water, and promoted the plant growth [11]. Flores [12] studied the effects of different rootstocks on tomato and found that the growth and development of the plants changed significantly, but the effects of different rootstock types on the plants were slightly different [10]. In this experiment, the scion treatment method can effectively increase the plant height of tomato offspring. Except for red scion, the root length of the treatment group was significantly higher than that of the control group, which was basically consistent with previous studies [13]. The red tomato treatment method reduced the stem base diameter of tomato, and yellow rootstock could effectively increase the stem base diameter of the offspring. Red scion could effectively increase the fresh weight of roots and stems of the offspring. Red rootstock could effectively increase the fresh weight of roots and leaves, and yellow tomato grafting method could effectively increase the fresh weight of roots, stems and leaves of tomato offspring. In terms of biomass, grafting could increase the root biomass of the offspring plants. In general, grafting increased the root-shoot ratio of tomato progeny and enhanced the root activity of the plant, which induced the tomato to regulate itself, which was beneficial to the tomato growth and passed on to the offspring.

Photosynthesis can synthesize organic matter to provide plants with the energy and material basis for growth and development, which is of great significance [14]. Leaf photosynthesis mainly depends on three 
physiological processes, including photosynthetic substrate $\mathrm{CO}_{2}$ conduction, photoreaction and dark reaction. Strong $\mathrm{CO}_{2}$ conductivity, higher photoreaction and dark reaction are the physiological basis for increasing photosynthetic rate in leaves [15]. The most direct response to the photosynthetic capacity is the difference in Pn. In this experiment, Pn of tomato grafting offspring tomato leaves was significantly higher than that of the control. Gs and Tr were also significantly higher, indicating that the grafted tomato leaves had stronger $\mathrm{CO}_{2}$ conductivity and higher light energy conversion rate. Pn in cucumber grafted seedlings was higher than that of self-rooted seedlings, indicating that grafting could increase the photosynthetic capacity of cucumber and had strong assimilation ability, which grounded strongly for the growth of cucumber plants [16]. In this experiment, different rootstock grafting had different effects on photosynthetic capacity of tomato. Overall, Pn, Gs and Tr showed an increasing trend, which was consistent with the results of Li Xiaohong's research [17].

In summary, grafting could improve the growth characteristics of the plants in the seedling stage, and could effectively improve the photosynthetic capacity of the leaves of the seedlings under Se stress. Among them, the best effect of yellow rootstock was to provide ideas and theoretical basis for the production of Se-enriched tomatoes in the Se-deficient areas in the future.

\section{References}

1. Committee of Chinese Academy of Sciences, Flora Reipublicae Popularis Sinicae. (1978) Flora Reipublicae Popularis Sinicae. Scinence Press, Beijing, China.

2. Zhang, W., Geng, Z.C. (2012) Research progress regarding the effect of exogenous Selenium on vegetables. Acta Hortic. Sin., 39: 1749-1756.

3. Shi, H.P., Zhang, Y.J., Liu, Z.S. (1993) Absorption, distribution and transformtion of Selenium in the tomato plants. Acta Bot. Sin., 7: 541-546.

4. Wang, S.Z., Zhao, X.R., Wang, X.Z., Wang,Y.J. (2008) Effects of spraying $\mathrm{NaSeO}_{3}$ on photosynthesis of leaves and yield and quality of garlic. Chin. Agric. Sci. Bul., 24.

5. Zhao, X., Zhao, B.L. (2000) Experimental study on the effect of pepper grafting. J. Northern Hortic., 4: 8-10.

6. Fallahi, E., Chun, I.J., Neilsen, G.H., Colt, W.M. (2001) Effects of three rootstocks on photosynthesis, leaf mineral nutrition, and vegetative growth of 'BC-2 FUJI' apple trees. J. Plant Nutr., 24: 827-834.

7. Tan, M.M., He, Z.Q., Zheng, W.G. (2014) Effects of grafting on photosynthetic characteristics and mineral elements of melon seedlings under copper stress. Acta Agric. Boreali-Sin., 29: 186-192.

8. Lin, L.J., Luo, L., Zhang, X., Yang, D.Y., Liao, M.A., Tang, F.Y. (2015) Effects of rape rootstock on cadmium accumulation characteristics of Capsella bursa-pastoris post-grafting generation. Acta Agric. Boreali-Sin., 30: 207-212.

9. Lin, L.J. (2015) Effects of intercropping with post-grafting generation of Solanum Photeinocarpum on Cadmium accumulation of loquat. Sichuan Agricultural University, Sichuan, China.

10. Liu D.X., Jing, X., Jiao, J., Wei, M., Sui, S.L., Zhao, L.H., Li, Y.W., Zhao,N., Gong, B., Shi, Q.H. (2017) Comprehensive evaluation of yield, quality and salt stress tolerance in grafting tomato. Acta Hortic. Sin., 44: 1094-1104.

11. Aloni, B., Cohen, R., Karni, L., AktAs, H., Edelstein, M. (2010) Hormonal signaling in rootstock-scion interactions. Sci. Hortic., 127: 119-126.

12. Flores, F.B., Sanchez-Bel, P., Estañ, M.T., Martine-Rodriguez, M.M, Moyano, E., Morales, B., Campos, F.J., Garcia-Abellán, J.O., Egea, M.I., Fernández-Garcia, N., Romojaro, F., Bolarín, M.C. (2010) The effectiveness of grafting to improve tomato fruit quality. Sci. Hortic., 125: 211-217.

13. Zhang, Y.X., Ren, M., Hong, Y.T. (2019) Effects of grafting with different rootstocks on growth and photosynthetic characteristics of Xianlajiao chili pepper. J. Northwest Sci-Tech Univ. Agric. For.(Nat. Sci. Ed), 47.

14. Bai, W.Y., Tie, L.H., Feng, M.S., Wang, Y.L., Li, W.B., Tan, F. (2018) Growth and photosynthetic characteristics of grafted Alnus seedlings from different provenances. J. of Sichuan Agric. Univ. 36: 46-51.

15. Nie, C.L., Chen, G.L. (2000) Study on growth trends and physiological characteristics of grafted watermelon seedling. Acta Agric. Boi-Occid. Sin. 2000.

16. Sun, Y., Huang, W., Tian, X.H., Wu, Y., Ding, Q., Zhou, C.T. (2002) Study on growth situation, photosynthetic characteristics and nutrient absorption characteristics of grafted cucumber seedlings. Plant Natr. Fert. Sci., 8:180-181.

17. Li, X.H., Zhou, K., Xie, Z. Li, H.X., Zhang, Z., Tao, J.M. (2009) Photosynthesis of Yatomi Rosa on eight grape rootstocks. J. Fruit Sci., 26: 90-93. 